\title{
The Distribution and Role of M1 and M2 Macrophages in Aneurysm Healing after Platinum Coil Embolization
}

\author{
(D) Z. Khashim, (DD. Daying, (DD.Y. Hong, (D).A. Ringler, (D). Herting, (DD. Jakaitis,
}

(DD. Maitland, (DD.F. Kallmes, and (D) Radirvel

\begin{abstract}
BACKGROUND AND PURPOSE: Impairment of macrophage polarization from a proinflammatory macrophage type 1 (MT) population to an anti-inflammatory macrophage type 2 (M2) population is a hallmark of poor wound healing. In this study, we aimed to evaluate the distribution of $\mathrm{M} 1$ and M2 macrophages and to analyze their association with healing in aneurysms embolized by endovascular coiling.

MATERIALS AND METHODS: Elastase-induced aneurysms were created in female rabbits and subsequently embolized with platinum coils. Aneurysm occlusions were evaluated with angiographic imaging at $1(n=6), 3(n=5)$, or $6(n=6)$ months. Aneurysm tissues were harvested for histologic analysis, quantification of M1 and M2 macrophages by immunofluorescence, and collagen deposition determined by Masson trichrome staining. Histologic grading of aneurysm healing was also performed. Untreated aneurysms were used as controls $(n=6)$.

RESULTS: The M1 macrophage population was highest at 1 month posttreatment, progressively decreasing at 3 and 6 months. The M2 macrophage population progressively increased at 3 and 6 months posttreatment. The highest collagen deposition was at 6 months posttreatment. We found a moderate-to-weak direct correlation between the percentage of M2 macrophages and collagen deposition, as well as total histologic scores overall, and a strongly positive direct correlation between the percentage of $\mathrm{M} 2$ macrophages and total histologic scores at 6 months posttreatment.
\end{abstract}

CONCLUSIONS: Our data support the direct correlation between M2 macrophage polarization and healing in aneurysm tissues. Our results show a positive relationship between M2 macrophage populations and total histologic scores at later stages of healing after endovascular coiling. We conclude that interventions aimed at stimulating M2 macrophage expression locally may improve aneurysm healing after coil embolization.

ABBREVIATIONS: $C D 80$ = cluster of differentiation 80; CD206 = cluster of differentiation 206; $M 1$ = macrophage type 1; M2 = macrophage type 2

E ndovascular coiling is a safe and effective treatment to achieve occlusion of saccular intracranial aneurysms. With time, however, incomplete occlusion and recurrence remain challenging obstacles to successful endovascular treatment. ${ }^{1,2}$ Several previous

Received March 27, 2020; accepted after revision June 4

From the Department of Radiology (Z.K., D.D., D.Y.H., J.A.R., D.J., D.F.K., R.K.), Mayo Clinic, Rochester, Minnesota; and Biomedical Engineering (S.H., D.M.), Texas A\&M University, College Station, Texas.

This study was supported by a grant from the National Institutes of Health (R01NS076491 and U01-NS089692) and, in part, by a fellowship award through the National Defense Science and Engineering Graduate Fellowship Program, sponsored by the Air Force Research Laboratory, the Office of Naval Research, and the Army Research Office.

Please address correspondence to Ramanathan Kadirvel, PhD, Department of Radiology, Mayo Clinic, 200 First St Southwest, Rochester, MN, 55905; e-mail: kadir@mayo.edu

- Indicates open access to non-subscribers at www.ajnr.org

http://dx.doi.org/10.3174/ajnr.A6719 studies have demonstrated associations between poor occlusion or recurrence of aneurysms and factors such as aneurysm size and volume, coil packing density, coil compaction, ${ }^{3,4}$ unorganized thrombus, blood pressure, lack of neointima formation, and regulation of cells. ${ }^{5,6}$ Few studies have evaluated the infiltration of inflammatory cells into the aneurysm dome during the healing process after endovascular coiling. ${ }^{7,8}$

Inflammatory cells are emerging as a topic of clinical interest in this area. Macrophages may be particularly valuable, due to the unique process of macrophage polarization and its potential impact on wound healing and tissue remodeling. The remarkable plasticity of macrophages enables these cells to change their form and functional phenotype from classically activated macrophage type 1 (M1) to alternatively activated macrophage type 2 (M2) in response to signals in their local environment. 9,10 
The regulation of macrophage subtype M1 (cluster of differentiation 80 [CD80]) and M2 (cluster of differentiation 206 [CD206]) markers has been studied in several disease models. ${ }^{11-14}$ Previous studies have demonstrated the persistence of a proinflammatory M1 macrophage population without a subsequent transition to an anti-inflammatory M2 phenotype in poorly healing wounds. Enhancement of T1 M2 macrophage polarization could be a potential therapeutic option in wound healing. ${ }^{15,16}$

In this study, we aimed to evaluate the distribution of M1 and M2 macrophages and to analyze their association with healing in aneurysms embolized by endovascular coiling.

\section{MATERIALS AND METHODS}

\section{Aneurysm Creation and Tissue Harvest}

Elastase-induced saccular aneurysms were created in $23 \mathrm{New}$ Zealand white female rabbits, weighing between 2.5 and $4 \mathrm{~kg}$. The procedures for aneurysm creation were performed as described previously. ${ }^{17}$ Aneurysms were permitted to mature for at least 3 weeks after creation. All treated aneurysms were embolized with the standard bare platinum coils as previously described. ${ }^{18}$ The animals were euthanized by lethal injection of pentobarbital at 1 month $(n=6), 3$ months $(n=5)$, or 6 months $(n=6)$ after endovascular treatment. Untreated control animals were sacrificed at 1 month $(n=3)$ and 3 months $(n=3)$. The harvested aneurysm tissue samples were fixed in $10 \%$ neutral buffered formalin, embedded in paraffin, and sectioned as previously described. ${ }^{19}$ Some of the rabbits used in this study were originally part of another investigation, in which bare platinum coils were used to treat the aneurysms. The original investigation was entirely unrelated to this project, ${ }^{20}$ and did not interfere with the goals of this study.

\section{Angiography}

DSA images were obtained immediately after coil implantation and just before sacrifice. The follow-up, presacrifice images were assessed by comparing them with the images after coil implantation using a 3-category grading system (stable occlusion, progressive occlusion, recanalization [coil compaction]).

\section{Immunofluorescence}

The paraffin-embedded tissue sections were mounted on microscope slides (Superfrost; Cardinal Health) and incubated for 2 hours at $56^{\circ} \mathrm{C}$. The slides were de-paraffinized with xylene and alcohol and washed with water. Antigen retrieval was performed by boiling at $95^{\circ} \mathrm{C}$ for 15 minutes in a $0.1-\mathrm{mol} / \mathrm{L}$ citric acid buffer. The slides were then blocked with appropriate blocking buffer for 30 minutes at room temperature. Slide sections were incubated overnight at $4^{\circ} \mathrm{C}$ in primary antibodies for M1 (CD80, 1:100 dilution, catalog number 8679; ProSci) or M2 (CD206, 1:50 dilution, catalog number AF2535; R\&D Systems). The slides were washed and incubated in secondary antibodies (Cy3; Jackson ImmunoResearch Laboratories) for 2 hours. The slides then were counterstained with nucleic acid stain (Hoechst 33258; Thermo Fisher Scientific) for 5 minutes, then washed, dehydrated, and mounted with mounting medium (Shandon Consul-Mount; Thermo Fisher Scientific). Five randomly assigned fields were chosen and captured on a FluoView FV1200 confocal microscope (Olympus
Aneurysm geometry results of all the study groups ${ }^{a}$

\begin{tabular}{lclcc}
\multicolumn{1}{c}{ Groups } & $\begin{array}{c}\text { Untreated } \\
\text { Control }\end{array}$ & $\begin{array}{c}\text { 1 Month } \\
\text { Postcoiling }\end{array}$ & $\begin{array}{c}\text { 3 Months } \\
\text { Postcoiling }\end{array}$ & $\begin{array}{c}\text { 6 Months } \\
\text { Postcoiling }\end{array}$ \\
\hline Neck width & $3.73 \pm 0.48$ & $3.0 \pm 0.71$ & $3.7 \pm 0.94$ & $3.6 \pm 1.79$ \\
Width & $4.18 \pm 0.84$ & $2.8 \pm 0.37^{\mathrm{b}}$ & $4.3 \pm 0.47$ & $3 \pm 0.51^{\mathrm{C}}$ \\
Height & $9.73 \pm 0.75$ & $9.3 \pm 1.06$ & $8.0 \pm 1.58$ & $7.7 \pm 2.11$ \\
\hline
\end{tabular}

${ }^{a}$ All data are reported as mean $(\mathrm{mm}) \pm \mathrm{SD}$.

${ }^{\mathrm{b}} P<.05$.

${ }^{c} p<.01$.

Life Science). Human tonsil was used as a positive control and for a negative control when the primary antibody was omitted. The number of positively staining cells in each image was counted manually by 3 separate individuals.

\section{Collagen Deposition}

Collagen deposition was analyzed quantitatively through Masson trichrome staining as previously described. ${ }^{21}$ The images were captured using microscopy imaging (RTV 5.0; Qimaging MicroPublisher). The images were analyzed using a recently described and experimentally verified image analysis technique, ${ }^{22}$ using Photoshop software (Adobe).

\section{Histologic Grading}

Histologic grading of aneurysm tissues was performed by an experienced reviewer ( $>15$ years of experience in aneurysm-specific pathology), and grading was followed according to the previously described protocol. ${ }^{21,23}$ Neck healing was based on both gross and microscopic inspection. The scores of the gross (0-3) and microscopic inspection (0-4) were averaged to yield a single neck score. If different areas of the aneurysm neck showed different levels of healing, intermediate scores (0.5) were used. Microcompaction assessment (0-3) was based on the shape of the coil mass across the neck, from concave to convex. Healing characteristics in the dome (0-5) were categorized on the basis of the density of cellular infiltration and the area of organized tissue. Accordingly, each score was added together to obtain a total histologic score, as described in Equation 1.

Equation 1: Calculation of total histologic score

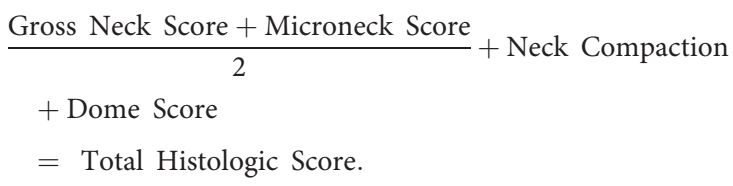

\section{Statistical Analysis}

All statistical analyses were performed using GraphPad Prism software (GraphPad Software). The differences between the treatment-to-sacrifice time groups were evaluated using the Student $t$ test. The strength of the linear relationships between M2 macrophages and both collagen deposition and histologic grading was evaluated using the Pearson correlation coefficient. Descriptive data were presented as means \pm standard error of mean. A $P$ value of $<.05$ was considered statistically significant. 

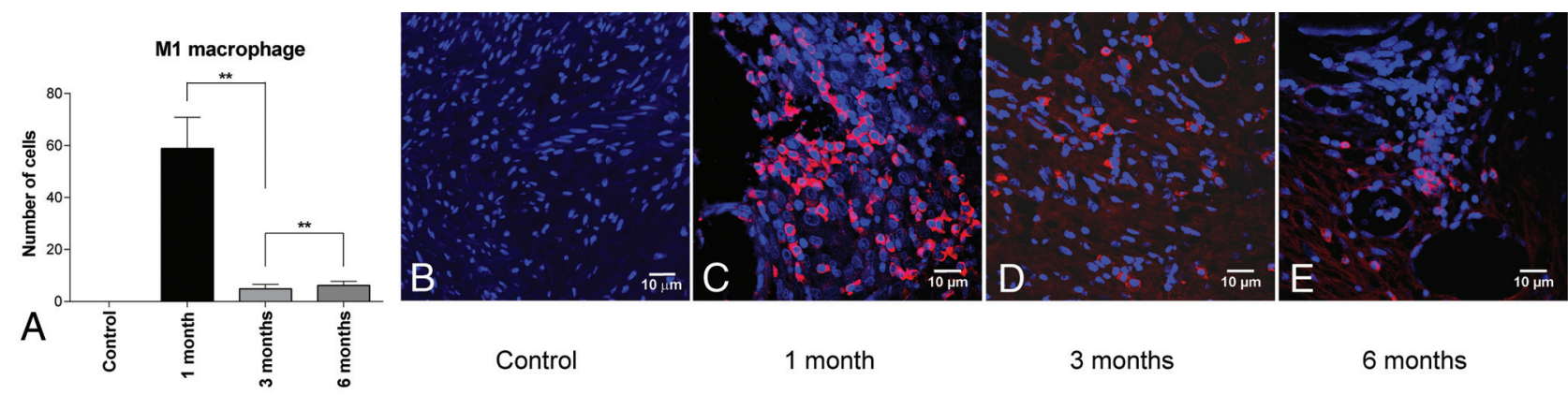

1 month

3 months

6 months
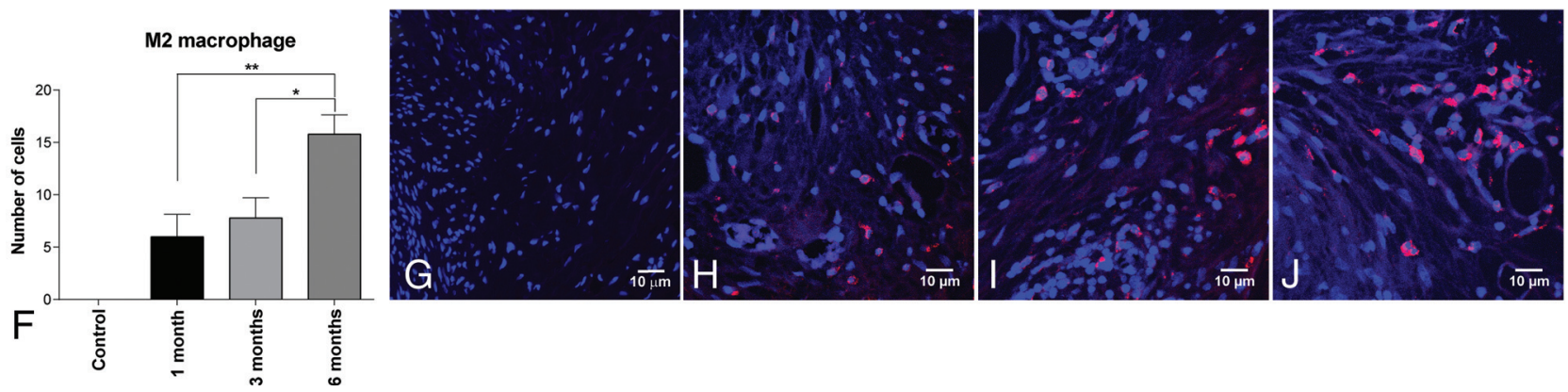

FIG 1. M1 and M2 macrophage populations in aneurysm tissues after endovascular coiling for control and treatment groups. A, Mean number of M1 macrophages \pm standard error of the mean. Representative confocal microscopy images of cells staining positive for CD80 (60 $\times$ oil magnification) at 1 month $(C), 3$ months $(D)$, and 6 months $(E)$. F, Mean number of M2 macrophages \pm standard error of the mean. Representative confocal microscopy images of cells staining positive for CD206 (60× oil magnification) at 1 month $(H), 3$ months $(I)$, and 6 months $(U) . B$ and $G$, Representative confocal images of control aneurysm tissues stained for CD 80 and CD206, respectively, at 1 month (20x oil magnification). Asterisk indicates $P<.05$; double asterisks, $P<.01$.
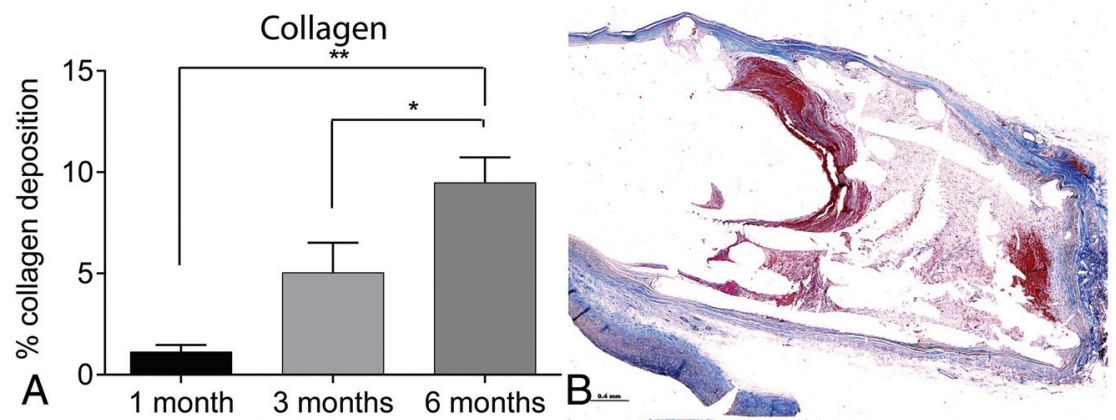

\section{RESULTS}

\section{Angiography}

Angiographic imaging of aneurysms before coiling indicated that the mean measurements did not differ significantly among the 3 treatment-to-sacrifice time groups (Table). Follow-up images obtained 1 month posttreatment demonstrated stable occlusion in 4/6 (66.7\%) aneurysms, progressive occlusion in $1 / 6(16.7 \%)$ aneurysms, and coil compaction in $1 / 6(16.7 \%)$ aneurysms. In the group sacrificed 3 months posttreatment, 5/5 (100\%) aneurysms showed stable occlusion. In the group sacrificed 6 months posttreatment, 5/6 (83.3\%) aneurysms showed stable occlusion and 1/6 aneurysms (16.7\%) showed progressive occlusion. All control, untreated aneurysms remained patent before sacrifice.

\section{M1 and M2 Macrophage Populations}

The mean number of proinflammatory M1 macrophages (CD80) found $(B), 3$ months $(C)$, and 6 months $(D)(2.5 \times$ magnification; scale bar $=0.4 \mathrm{~mm})$. Asterisk indicates $P<.05$; double asterisks, $P<.01$. 
in the 1-month posttreatment group $(58.86 \pm 29.52)$ was significantly higher compared with both the 3-month posttreatment group $(4.96 \pm 3.79, P=.003)$ and the 6-month posttreatment group $(6.2 \pm 3.67, P<.01)$ (Fig 1). The number of M1

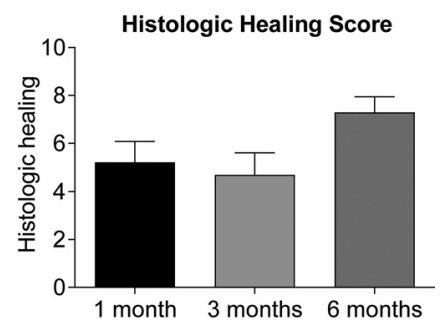

FIG 3. Total histologic healing scores for aneurysm tissues after endovascular coiling for 3 treatment-to-sacrifice time groups. macrophages did not differ significantly between the 3- and 6month groups $(P=.587)$. In contrast, the mean number of antiinflammatory M2 macrophages (CD206) was significantly higher in the 6-month posttreatment group $(15.8 \pm 4.50)$ compared with both the 1 -month group $(6 \pm 5.23, P<.01)$ and the 3 month group $(7.8 \pm 4.32, P=.015)$. No significant differences were observed between 1 and 3 months $(P=.555)$. There were no positively staining cells observed in the untreated aneurysm control group for either M1 or M2 markers (Fig 1B).

\section{Collagen Deposition}

The mean percentage of collagen deposition was significantly higher in the 6-month posttreatment group $(9.48 \pm 3.07 \%)$ compared with both the 1-month $(1.14 \pm 0.81 \%, P<.001)$ and 3 month $(7.43 \pm 3.29 \%, P<.05)$ posttreatment groups (Fig 2). No significant difference was observed between 1 and 3 months posttreatment $(P>.05)$
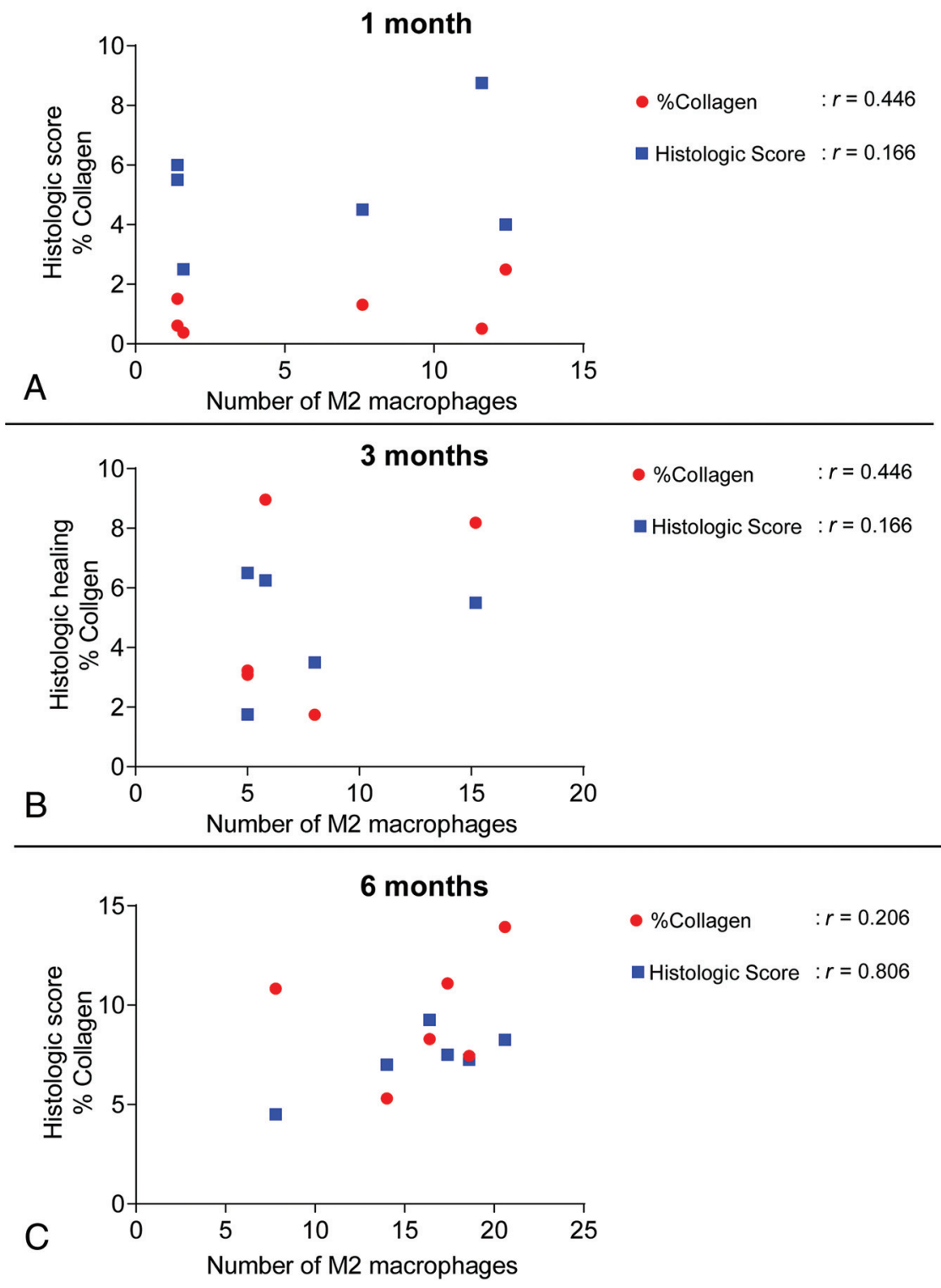

FIG 4. Correlational relationships of M2 macrophages to collagen deposition and histologic grading in aneurysm tissues after endovascular coiling for 3 treatment-to-sacrifice time groups. $A$, One month posttreatment. $B$, Three months posttreatment. $C$, Six months posttreatment.

\section{Histologic Grading}

The mean total histologic scores at 1 month posttreatment $(5.21 \pm 2.12)$ did not differ significantly compared with the 3-month $(4.7 \pm 2.03, P>.05)$ or 6 -month $(7.3 \pm 1.59, P>.05)$ posttreatment groups (Fig 3). There was also no significant difference between the 3- and 6-month posttreatment groups $(P>.05)$.

\section{M2 Macrophages and Correlations with Collagen} Deposition and Histologic Grading The prevalence of M2 macrophages had a moderately positive correlation with collagen deposition in both the 1month $(r=0.450)$ and the 3-month ( $r=0.446)$ posttreatment groups (Fig 4). A weak positive correlation between M2 macrophages and collagen deposition was observed in the 6-month posttreatment group $(r=0.206)$. M2 macrophages were strongly positively correlated with the total histologic grading score in the 6-month posttreatment group ( $r=0.806)$; this relationmonth $(r=0.166)$ and 1-month $(r=$ $0.323)$ posttreatment groups.

\section{DISCUSSION}

In this study, we found that the presence of proinflammatory M1 macrophages in aneurysm tissues was significantly higher at 1 month after endovascular coiling compared with 3 or 6 months posttreatment. In contrast, the prevalence of anti-inflammatory ship was weakly positive in the 3 - 
M2 macrophages was highest at 6 months after endovascular coiling. These findings demonstrate that macrophage polarity is skewed toward the M1 phenotype in aneurysms on initial tissue damage, whereas M2 macrophages predominate in the later healing phases of tissue formation and remodelling. ${ }^{9,24}$ The M2 macrophage phenotype has been found to be important for promoting wound healing and tissue repair and for resolving inflammation. ${ }^{9}$ Studies have suggested that increasing the ratio of M2-to-M1 macrophages in wounds can accelerate the healing process. This has been demonstrated experimentally by reducing the effects of endogenous M1 macrophages using neutralizing antibodies or by delivering exogenous polarized M2 macrophages to stimulate wound healing in animal models. ${ }^{25,26}$ Previous approaches using proinflammatory coatings on inert platinum coils showed promise in some preclinical models, ${ }^{27,28}$ succeeding in stimulating inflammation in clinical trials but failing to reduce recurrence rates, ${ }^{29,30}$ possibly due to an unfavorable balance between M1 and M2 macrophages. Coil-mediated delivery of the proinflammatory cytokine, monocyte chemotactic protein-1, has been shown to accelerate aneurysm healing through macrophage inflammatory protein- $1 \alpha$ and macrophage inflammatory protein-2-dependent pathways in a mouse model. ${ }^{27}$ Our findings suggest that similar interventions aimed at stimulating M2 polarization may improve aneurysm healing after treatment. However, a robust study is needed to delineate the role of M2 macrophage activation in a coil-implanted aneurysm.

We also found that the percentage of collagen deposition progressively increased with time, with statistically significant differences at both 3 and 6 months after treatment. These data are consistent with the findings of a previous study in which we reported that the aneurysm dome became acellular and vascularized with visualized connective tissue and observed increased collagen deposition 3 months after endovascular coiling. ${ }^{31}$ Additionally, we have previously demonstrated that collagen synthesis and increased histologic scores are associated with improved healing of aneurysms. ${ }^{19,31}$ One way in which M2 macrophages could be involved in this healing process is through secretion of transforming growth factor $\beta 1$. Factors like transforming growth factor $\beta 1$ induce the proliferation of fibroblasts, which differentiate into myofibroblasts. These cells are responsible for collagen production and closure of skin wounds. ${ }^{10}$ Thus, in this study, we evaluated any potential correlation between M2 macrophage polarity and collagen deposition. Our data demonstrate a moderate-to-weak positive correlation between M2 macrophages and collagen deposition in each of the 3 treatment-to-sacrifice time groups and a strongly positive correlation between M2 macrophages and the total histologic score at 6 months posttreatment. These findings suggest that the activity of M2 macrophages in aneurysm wound healing is not limited to collagen deposition but may also be aided by other mechanisms, such as promoting secretion of platelet-derived growth factor, chemoattractant stabilizing pericytes, extracellular matrix deposition and augmentation, and sprouting endothelial cells. ${ }^{24,32}$ In the control group, as expected, we did not find any M1 or M2 macrophages because inflammation is absent in the rabbit "untreated" aneurysm wall beyond 2 weeks following the model creation. ${ }^{33}$ Coil treatment itself increases the inflammatory response in the rabbit model. ${ }^{34}$ Our findings indicate that M1 and M2 macrophage levels are due to tissue responses to coil implants.
This study has several limitations. It focused exclusively on M1 and M2 macrophage numbers in relation to collagen deposition and total histologic scoring in coil-embolized aneurysms. We did not study the correlation between M1/M2 polarization and the recurrence rate, due to the small sample size. Furthermore, highthroughput microarray or gene profiling will facilitate a better understanding of the underlying mechanisms of the M2 phenotype switch. However, in the current preliminary work, we have only analyzed the distribution of the macrophage subtype (M1 and M2) population in the coil-treated aneurysm environment. A more indepth study of macrophage subtypes and other immune cells involved in aneurysm healing will give us a deeper understanding of aneurysm healing after coil implantation. All of our current observations are based on animal aneurysm tissues; studying the distribution of macrophage subtypes in human aneurysm tissues will be more directly applicable for future therapeutic approaches.

\section{CONCLUSIONS}

We found that the number of M2 macrophages had a strong positive correlation with total histologic scores at a later stage of healing (6 months) after embolization treatment in a rabbit aneurysm model. This finding provides an important impetus for further studies aimed at understanding possible associations between M2 macrophages and other vascular components involved in the healing of coil-embolized aneurysms.

\section{ACKNOWLEDGMENTS}

The authors acknowledge Superior Medical Experts for editing assistance.

Disclosures: Scott Herting-RELATED: Grant: Department of Defense, National Defense Science and Engineering Graduate Fellowship, Comments: The National Defense Science and Engineering Graduate fellowship supported me by providing tuition and stipends during graduate school. Duncan Maitland-RELATED: Grant: National Institutes of Health, Comments: National Institute of Neurological Disorders and Stroke, Grant/Award No.: U01-NS089692*; UNRELATED: Board Membership: Shape Memory Medical Inc, Comments: Shape Memory Medical Inc (shapemem.com) is commercializing neuorvascular and other vascular occlusion devices. These devices and Shape Memory Medical Inc were not involved in the work in this article. I am a cofounder and board member at Shape Memory Medical Inc; Patents (Planned, Pending or Issued): Texas A\&M University and Lawrence Livermore National Laboratory, Comments: I have 40 issued patents and many pending related to vascular occlusion technology. None of the technology that 1 developed was part of this work; Royalties: Texas A\&M University and Lawrence Livermore National Laboratory, Comments: I receive licensing royalty payments from the license of vascular occlusion technology by Shape Memory Medical Inc, paid to my former (Lawrence Livermore) and current (Texas A\&M) employers. None of my licensed principal investigator was involved in this work; Stock/Stock Options: Shape Memory Medical Inc, Comments: I own stock and stock options in Shape Memory Medical Inc. Shape Memory Medical Inc was not involved in this article. David F. Kallmes - UNRELATED: Grants/Grants Pending: Medtronic, MicroVention, NeuroSigma, Neurogami, Comments: preclinical aneurysm research support.* Ram Kadirvel—RELATED: Grant: National Institutes of Health.* *Money paid to the Institution.

\section{REFERENCES}

1. Crobeddu E, Lanzino G, Kallmes DF, et al. Review of 2 decades of aneurysm-recurrence literature, part 1: reducing recurrence after endovascular coiling. AJNR Am J Neuroradiol 2013;34:266-70 CrossRef Medline 
2. Crobeddu E, Lanzino G, Kallmes DF, et al. Review of 2 decades of aneurysm-recurrence literature, Part 2: managing recurrence after endovascular coiling. AJNR Am J Neuroradiol 2013;34:481-85 CrossRef Medline

3. Knap D, Gruszczyńska K, Partyka R, et al. Results of endovascular treatment of aneurysms depending on their size, volume and coil packing density. Neurol Neurochir Pol 2013;47:467-75 CrossRef Medline

4. Leng B, Zheng Y, Ren J, et al. Endovascular treatment of intracranial aneurysms with detachable coils: correlation between aneurysm volume, packing, and angiographic recurrence. J NeuroIntervent Surg 2014;6:595-99 CrossRef Medline

5. Ozawa T, Tamatani S, Koike T, et al. Histological evaluation of endothelial reactions after endovascular coil embolization for intracranial aneurysm: clinical and experimental studies and review of the literature. Interv Neuroradiol 2003;9:69-82 CrossRef Medline

6. Boecher-Schwarz HG, Ringel K, Kopacz L, et al. Ex vivo study of the physical effect of coils on pressure and flow dynamics in experimental aneurysms. AJNR Am J Neuroradiol 2000;21:1532-36 Medline

7. Ishihara $S$, Mawad ME, Ogata $K$, et al. Histopathologic findings in human cerebral aneurysms embolized with platinum coils: report of two cases and review of the literature. AJNR Am J Neuroradiol 2002;23:970-74 Medline

8. Shimizu S, Kurata A, Takano M, et al. Tissue response of a small saccular aneurysm after incomplete occlusion with a Guglielmi detachable coil. AJNR Am J Neuroradiol 1999;20:546-48 Medline

9. Ferrante CJ, Leibovich SJ. Regulation of macrophage polarization and wound healing. Adv Wound Care (New Rochelle) 2012;1:10-16 CrossRef Medline

10. Hesketh M, Sahin KB, West ZE, et al. Macrophage phenotypes regulate scar formation and chronic wound healing. Int J Mol Sci 2017;18:1545 CrossRef Medline

11. Zhou Y, Yoshida S, Kubo Y, et al. Different distributions of M1 and M2 macrophages in a mouse model of laser-induced choroidal neovascularization. Mol Med Rep 2017;15:3949-56 CrossRef Medline

12. Nawaz A, Aminuddin A, Kado T, et al. CD206(+) M2-like macrophages regulate systemic glucose metabolism by inhibiting proliferation of adipocyte progenitors. Nat Commun 2017;8:286 CrossRef Medline

13. Trombetta AC, Soldano S, Contini $\mathrm{P}$, et al. A circulating cell population showing both M1 and M2 monocyte/macrophage surface markers characterizes systemic sclerosis patients with lung involvement. Respir Res 2018;19:186 CrossRef Medline

14. Raggi F, Pelassa S, Pierobon D, et al. Regulation of human macrophage M1-M2 polarization balance by hypoxia and the triggering receptor expressed on myeloid cells-1. Front Immunol 2017;8:1097 CrossRef Medline

15. Khanna S, Biswas S, Shang Y, et al. Macrophage dysfunction impairs resolution of inflammation in the wounds of diabetic mice. PLoS One 2010;5:e9539 CrossRef Medline

16. Mirza R, Koh TJ. Dysregulation of monocyte/macrophage phenotype in wounds of diabetic mice. Cytokine 2011;56:256-64 CrossRef Medline

17. Altes TA, Cloft HJ, Short JG, et al. 1999 ARRS Executive Council Award: creation of saccular aneurysms in the rabbit-a model suitable for testing endovascular devices. American Roentgen Ray Society. AJR Am J Roentgenol 2000;174:349-54 CrossRef Medline

18. Kallmes DF, Helm GA, Hudson SB, et al. Histologic evaluation of platinum coil embolization in an aneurysm model in rabbits. Radiology 1999;213:217-22 CrossRef Medline
19. Dai D, Ding YH, Kadirvel R, et al. Relationship between aneurysm volume and histologic healing after coil embolization in elastaseinduced aneurysms: a retrospective study. AJNR Am J Neuroradiol 2008;29:98-101 CrossRef Medline

20. Herting SD, Boyle AJ, Dai D, et al. In vivo comparison of shape memory polymer foam-coated and bare metal coils for aneurysm occlusion in the rabbit elastase model. J Biomed Mater Res B Appl Biomater2019;107:2466-75 CrossRef Medline

21. Dai D, Yong-Hong D, Rezek I, et al. Healing of saccular aneurysms following platinum coil embolization: lack of improved efficacy with vitamin C supplementation. J Neurointerv Surg 2013;5:591-96 CrossRef Medline

22. Dai D, Ding YH, Danielson MA, et al. Endovascular treatment of experimental aneurysms with use of fibroblast transfected with replication-deficient adenovirus containing bone morphogenetic protein-13 gene. AJNR Am J Neuroradiol 2008;29:739-44 CrossRef Medline

23. Dai D, Ding YH, Lewis DA, et al. A proposed ordinal scale for grading histology in elastase-induced, saccular aneurysms. AJNR Am J Neuroradiol 2010;31:132-38 CrossRef Medline

24. Murray PJ, Wynn TA. Protective and pathogenic functions of macrophage subsets. Nat Rev Immunol 2011;11:723-37 CrossRef Medline

25. Goren I, Muller E, Schiefelbein D, et al. Systemic anti-TNFalpha treatment restores diabetes-impaired skin repair in ob/ob mice by inactivation of macrophages. J Invest Dermatol 2007;127:2259-67 CrossRef Medline

26. Jetten N, Roumans N, Gijbels MJ, et al. Wound administration of M2-polarized macrophages does not improve murine cutaneous healing responses. PLoS one 2014;9:e102994 CrossRef Medline

27. Hoh BL, Hosaka K, Downes DP, et al. Monocyte chemotactic protein-1 promotes inflammatory vascular repair of murine carotid aneurysms via a macrophage inflammatory protein-1alpha and macrophage inflammatory protein-2-dependent pathway. Circulation 2011;124:224352 CrossRef Medline

28. Murayama Y, Tateshima S, Gonzalez NR, et al. Matrix and bioabsorbable polymeric coils accelerate healing of intracranial aneurysms: long-term experimental study. Stroke 2003;34:2031-37 CrossRef Medline

29. McDougall CG, Johnston SC, Gholkar A, et al; MAPS Investigators. Bioactive versus bare platinum coils in the treatment of intracranial aneurysms: the MAPS (Matrix and Platinum Science) trial. AJNR Am J Neuroradiol 2014;35:935-42 CrossRef Medline

30. Pierot L, Cognard C, Ricolfi F, et al. CLARITY investigators. Mid-term anatomic results after endovascular treatment of ruptured intracranial aneurysms with Guglielmi detachable coils and Matrix coils: analysis of the CLARITY series. AJNR Am J Neuroradiol 2012;33:46973 CrossRef Medline

31. Brinjikji W, Kallmes DF, Kadirvel R. Mechanisms of healing in coiled intracranial aneurysms: a review of the literature. AJNR Am J Neuroradiol 2015;36:1216-22 CrossRef Medline

32. Spiller KL, Anfang RR, Spiller KJ, et al. The role of macrophage phenotype in vascularization of tissue engineering scaffolds. Biomaterials 2014;35:4477-88 CrossRef Medline

33. Kadirvel R, Ding YH, Dai D, et al. The influence of hemodynamic forces on biomarkers in the walls of elastase-induced aneurysms in rabbits. Neuroradiology 2007;49:1041-53 CrossRef Medline

34. Herting SM, Ding Y, Boyle AJ, et al. In vivo comparison of shape memory polymer foam-coated and bare metal coils for aneurysm occlusion in the rabbit elastase model. J Biomed Mater Res Part B Appl Biomater 2019;107:2466-75 CrossRef Medline 